\title{
Risk-informed local action planning against flooding: lessons learnt and way forward for a case study in Spain
}

\author{
J.T. Castillo-Rodríguez ${ }^{1, a}$, J.R. Porta-Sancho ${ }^{2}$, S. Perales-Momparler ${ }^{3}$ and I. Escuder-Bueno ${ }^{1,4}$ \\ ${ }^{1}$ Research Institute of Water and Environmental Engineering (IIAMA), Universitat Politècnica de València (UPV), Camino de Vera s/n, \\ 46022 Valencia, Spain \\ ${ }^{2}$ Department of Urban Planning, Infrastructures and Environment, Oliva City Council, Spain \\ ${ }^{3}$ GreenBlueManagement, Valencia, Spain \\ ${ }^{4}$ iPresas Risk Analysis, Spin-off UPV, Valencia, Spain
}

\begin{abstract}
After 29 years of the largest flood event in modern times (with the highest recorded rainfall rate at the Iberian Peninsula with $817 \mathrm{~mm}$ in 24 hours), the municipality of Oliva faces the challenge of mitigating flood risk through the development and implementation of a local action plan, in line with other existent and ongoing structural measures for flood risk reduction. Located $65 \mathrm{~km}$ from Valencia, on the South-Eastern coast of Spain, Oliva is affected by pluvial, river and coastal flooding and it is characterized by a complex and wide-ranging geography and high seasonal variation in population. A quantitative flood risk analysis has been performed to support the definition of flood risk management strategies. This paper shows how hazard, exposure and vulnerability analyses provide valuable information for the development of a local action plan against flooding, for example by identifying areas with highest societal and economic risk levels. It is concluded that flood risk management actions, such as flood warning and monitoring or evacuation, should not be applied homogenously at local scale, but instead actions should be adapted based on spatial clustering. Implications about the impact of education and training on flood risk reduction are also addressed and discussed.
\end{abstract}

\section{Introduction}

Local governments in Europe are facing multiple challenges regarding risk mitigation from natural hazards. Actions are changing from just reacting to regional, national or European requirements to more active strategies towards improved risk management.

However, while the roles and responsibilities of municipal governments regarding flood risk management have grown, there is still a lack of tools to support local flood risk analysis (e.g. required analyses are complex and time-consuming).

This is the case of the municipality of Oliva. Flood risk management is a key aspect for Oliva's current and future development. The goal of flood risk reduction poses a challenge for local authorities, as local economy depends highly on industries and tourism. In addition, Oliva's population is expected to grow, age, and become more diverse, with specific characteristics due to highly seasonal variability.

Over the last 10 years, Oliva City Council has promoted several studies to characterize flood hazards at local scale. However, a comprehensive flood risk analysis was still required.

In 2015, an ad-hoc quantitative flood risk analysis was conducted to provide local authorities with the information needed for developing a local action plan against flood risk and to evaluate the impact of ongoing structural measures on flood risk.

This paper summarizes the results of this analysis and the main aspects for implementing, updating and upgrading the plan.

\section{Local flood risk management plans}

\subsection{The context}

In 1999, the regional government approved the Special Plan against flood risk. This plan, reviewed in 2010, required all municipalities classified in high or medium flood risk levels (Table 1) to develop and implement a local action plan against flood risk. In addition, all municipalities potentially affected by flooding due to dam failure or mission disruption should develop this plan in line with Dam Emergency Action Plans (as established by the 1995 Spanish Directive on Civil Protection Planning). Up to 2015, there are 18 (out of 136) approved local action plans at the Valencian Autonomous Region, and 27 approved Dam Emergency Action Plans.

\footnotetext{
${ }^{\mathrm{a}}$ Corresponding author: jecasrod@upv.es
} 


\begin{tabular}{|c|c|}
\hline Risk level & Number of municipalities \\
\hline High & 48 \\
\hline Medium & 88 \\
\hline Low & 163 \\
\hline No risk & 243 \\
\hline Total & 542 \\
\hline
\end{tabular}

Table 1. Flood risk classification based on 2010 Special Plan

Oliva has been historically affected by flooding. In 1987, a flood event with $817 \mathrm{~mm}$ in 24 hours was recorded (highest record at the Iberian Peninsula).

Fig.1 shows registered maximum annual daily rainfall rates in Oliva (mm) within the period 1940-2009.

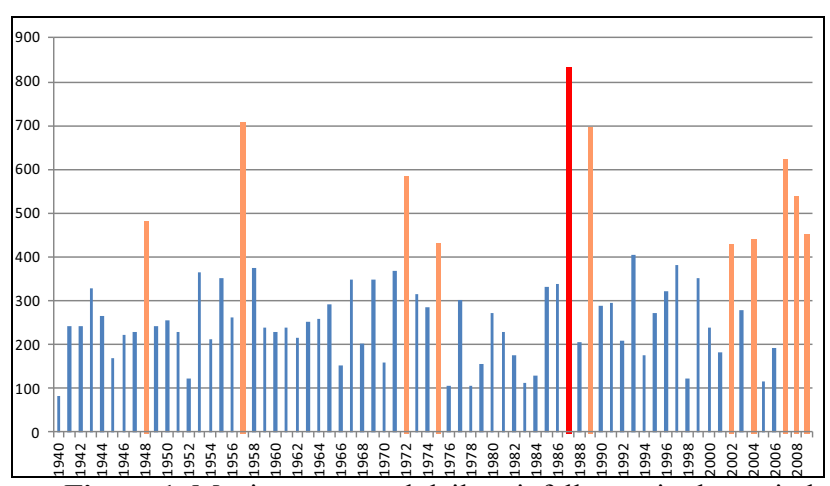

Figure 1. Maximum annual daily rainfall rates in the period 1940-2009. Source: (Oliva City Council, 2015).

Registered flood events in the period 1972-2014 include 18 events from river flooding and 7 from coastal flooding, mainly concentrated from September to December.

Oliva is classified as medium flood risk based on regional flood risk legislation. The municipality of Oliva faces the challenge of mitigating flood risk through the development and implementation of a local action plan, in line with other existent and ongoing structural measures for flood risk reduction (a concrete gravity dam is currently under construction and additional structural measures have been conducted within the urban area).

In addition to aforementioned context, a Territorial Action Plan against Flood Risk was approved in 2003 (PATRICOVA, by its acronym in Spanish), with the aim of promoting a risk-informed urban planning. This Plan classified potential affected areas in 6 hazard levels (Table 2), based on flood frequency and flood depth.

\begin{tabular}{|c|c|c|c|}
\hline & \multicolumn{3}{|c|}{ Flood frequency (return period) } \\
\hline Magnitude & $\mathbf{1 0 0 - 5 0 0 ~ \mathbf { ~ r ~ }}$ & $\mathbf{2 5 - 1 0 0 ~ y r}$ & $<\mathbf{2 5} \mathbf{~ y r}$ \\
\hline $\begin{array}{c}\text { Flood depth } \\
(>0.8 \mathrm{~m})\end{array}$ & 6 & 4 & 3 \\
\hline $\begin{array}{c}\text { Flood depth } \\
(<0.8 \mathrm{~m})\end{array}$ & 5 & 2 & 1 \\
\hline
\end{tabular}

Table 2. Hazard level classification. based on regional legislation.

This Plan was reviewed in 2015 (Generalitat Valenciana, 2015), incorporating a qualitative flood risk classification for all municipalities. Oliva is classified within the top 25 municipalities with highest flood risk, based on this recent classification.

\subsection{The challenge}

Oliva is a complex system with multiple urbanized areas. Different river courses, brooks and secondary river courses are found thus flood events may develop in different ways depending on storm characteristics, affecting one or several river basins.

In addition, the urban area presents a wide-ranging urban distribution, with highly vulnerable uses (e.g. campsites) in flood prone areas and changing population rates during the year.

\subsection{The opportunity: Risk-informed decisions}

In recent years, local authorities have promoted and developed several studies to characterize flood hazards at local scale, with high-detailed spatial resolution and multiple site visits.

A hydraulic model was performed in 2012 to obtain flood maps for 3 events (return period of 25-, 100- and 500-yr).



Figure 2. Location of the study area. Adapted from (Castillo-Rodríguez et al., 2016) 
In addition, up-to-date GIS-based data on land use distribution is available.

Based on recent experiences on risk-informed local flood action planning in Spain (Escuder-Bueno et al., 2012), an ad-hoc flood risk analysis was conducted by the authors to estimate flood risk and analyze the impact on risk of on-going structural and planned non-structural measures.

\section{Flood risk analysis for the city of Oliva}

Located $65 \mathrm{~km}$ from Valencia (Fig. 2), on the SouthEastern coast of Spain, Oliva is affected by pluvial, river and coastal flooding.

Table 3 includes the main characteristics of Oliva in terms of population and surface.

\begin{tabular}{|c|c|}
\hline $\begin{array}{c}\text { Population in } 2013 \\
\text { (resident) }\end{array}$ & 27,127 \\
\hline $\begin{array}{c}\text { Population in } 2013 \\
\text { (seasonal) }\end{array}$ & 55,174 \\
\hline Surface $\left(\mathrm{km}^{2}\right)$ & 59.61 \\
\hline Number of households & 20,185 \\
\hline $\begin{array}{c}\text { Capacity in hotels and } \\
\text { campsites }\end{array}$ & 5,913 \\
\hline
\end{tabular}

Table 3. Facts.

\subsection{Flood risk analysis}

The flood risk analysis has been developed following the procedure proposed in (Castillo-Rodríguez et al., 2014).

Two scenarios are considered:

-Base Case (BC): situation with structural measures for flood risk reduction (including the construction of a concrete gravity dam upstream the city).

-PAMRI: situation after implementing a Local Action Plan against Flood Risk (herein denoted as PAMRI, by its acronym in Spanish). It includes a reduction on vulnerability due to improved communication schemes, improved warning, and risk awareness through information campaigns.

Additional scenarios and sensitivity analyses were conducted and are further described in (CastilloRodríguez et al., 2016). In this paper, scenarios used for the development of the Local Action Plan are summarized.

\subsubsection{Flood hazard}

After reviewing historical flooding and conducted hydrologic and hydraulic studies, three flood scenarios (with return periods of 25, 100 and 500 years) are considered based on available results from recent hydraulic modelling.

This range of flood events is also used in regional and national flood risk management planning.
It is acknowledged that a wider range of flood scenarios would be desirable in future upgrades and further analyses (Ward et al., 2011).

Figure 3 shows the hazard level classification for Oliva published by regional policy, based on flood frequency (return period of 25, 100 or $500 \mathrm{yr}$ ) and flood depth (above or below $0.8 \mathrm{~m}$ ). Seven categories are considered (from NP1 to NP6, with an additional category for geomorphologic risk).

Flooding areas shown in Figure 3 were obtained from a hydraulic model at regional scale.

Figure 4 shows results in terms of hazard level classification, based on outcomes from the hydraulic model performed in 2012. Table 4 includes the estimated affected population per hazard level category (these values do not include potential population in hotels and campsites).

The comparison of both figures denotes differences between outcomes from hydraulic models. Using results from the regional study would underestimate flood risk in urbanized areas, mainly located in lowland areas and along the coast.

\begin{tabular}{|c|c|c|}
\hline $\begin{array}{c}\text { Hazard level } \\
\text { (NP) }\end{array}$ & $\begin{array}{c}\text { Resident } \\
\text { population }\end{array}$ & $\begin{array}{c}\text { Seasonal } \\
\text { population }\end{array}$ \\
\hline 1 & 17 & 55 \\
\hline 2 & 29 & 212 \\
\hline 3 & 1,743 & 5,520 \\
\hline 4 & 914 & 3,953 \\
\hline 5 & 16 & 137 \\
\hline 6 & 1,605 & 7,918 \\
\hline \multicolumn{2}{|c|}{ Table 4. Affected population per hazard level. }
\end{tabular}

\subsubsection{Vulnerability}

Vulnerability analysis has been developed following the procedure proposed by the Spanish Ministry of Agriculture, Food and Environment for developing flood risk management plans at river basin scale (MAGRAMA, 2013). The method is based on the approach proposed by DEFRA (DEFRA, 2006; Penning-Rowsell et al., 2005).

Consequence analysis in terms of life-loss included the estimation of:

- Affected population (including resident and seasonal population, and people in hotels and campsites)

- Hazard rates (based on flood depth, velocity and a debris factor). as defined by DEFRA (DEFRA, 2006)

- Area vulnerability factor (based on building typology, warning times and river basin characteristics)

- Population vulnerability factor (based on population age)

- Number of injured people

- Fatality rates

- Potential life-loss 


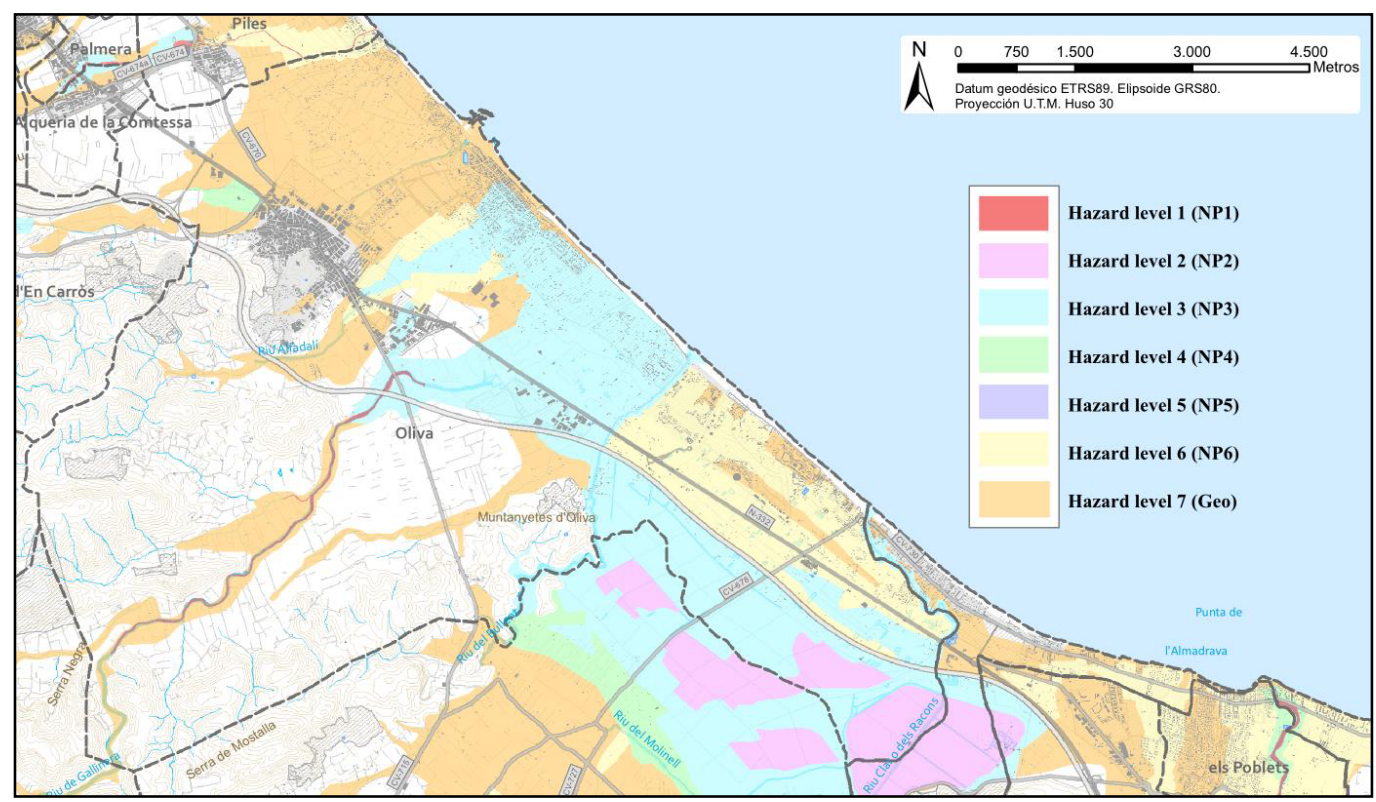

Figure 3. Hazard level map (NP distribution): regional scale. Adapted from (Generalitat Valenciana, 2015)

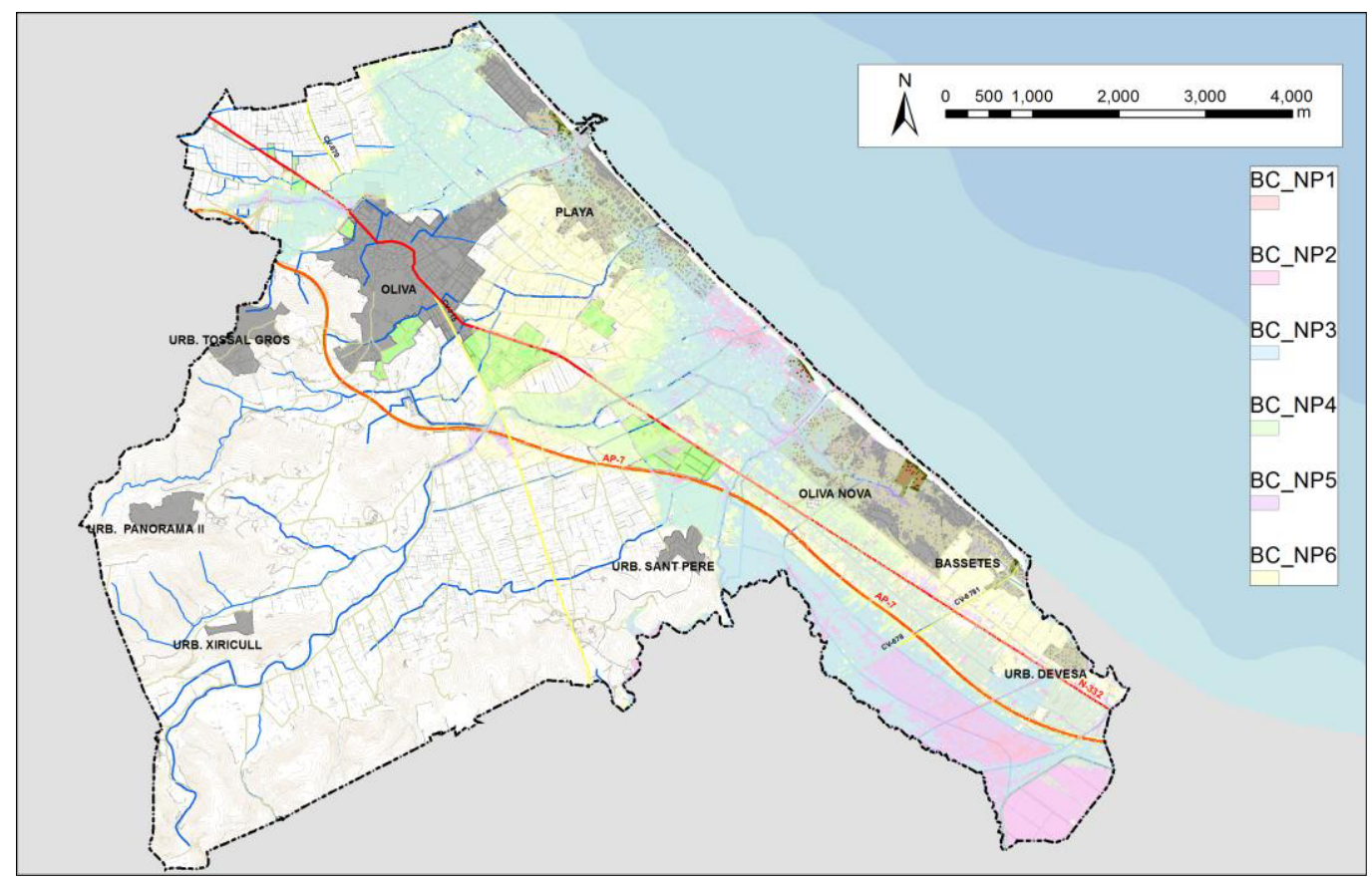

Figure 4. Hazard level map (NP distribution): city scale. Results for the Base Case (BC).

From population density rates in urbanized areas and distribution of households, affected population is estimated for three flood scenarios and two time categories (summer and winter, respectively).

Table 5 shows the estimated affected population (AP) and damage costs (in million EUR) per flood event, including potential population in hotels and campsites (35\% and $75 \%$ of occupancy is considered for winter and summer seasons, respectively).
It is assumed that damage costs do not differ from summer to winter seasons.

Consequence analysis in terms of economic damages included the estimation of the following factors:

- Affected area per land use type

- Percentage of damage (based on a generic depthdamage curve, used in regional studies)

- Reference cost per land use type.

- Direct damage costs 
- Indirect damage costs (based on the estimation of indirect costs from flooding for all municipalities at regional scale, depending on resident and seasonal population and economic activities within the urban area).

- Total economic damages

\begin{tabular}{|c|c|c|c|}
\hline \multirow{2}{*}{ Season } & $\begin{array}{c}\text { Return } \\
\text { period (yr) }\end{array}$ & $\begin{array}{c}\text { AP } \\
\text { (inh.) }\end{array}$ & $\begin{array}{c}\text { Damage } \\
\text { costs } \\
\text { (M EUR) }\end{array}$ \\
\hline \multirow{2}{*}{$\begin{array}{c}\text { Summer } \\
\text { (seasonal } \\
\text { population) }\end{array}$} & 100 & 5596 & 8.7 \\
\cline { 2 - 4 } & 500 & 18754 & 47.1 \\
\hline \multirow{2}{*}{$\begin{array}{c}\text { Winter } \\
\text { (resident } \\
\text { population) }\end{array}$} & 100 & 1572 & 8.7 \\
\cline { 2 - 4 } & 500 & 4497 & 17.3 \\
\hline
\end{tabular}

Table 5. Affected population and economic damage costs per flood event.

\subsubsection{Risk calculation and results}

The software tool iPresas UrbanSimp, a simplified version of iPresas Calc, first developed at the Polytechnic University of Valencia (Spain) and now by iPresas Risk Analysis, was used for risk calculations (iPresas Risk Analysis, 2014).

Table 6 shows results in terms of expected annual fatalities (societal risk in number of potential fatalities per year) and damages (economic risk in million EUR per year) for two scenarios: before (Base Case) and after implementing the Local Action Plan (PAMRI).

\begin{tabular}{|c|c|c|}
\hline & Base Case & PAMRI \\
\hline $\begin{array}{c}\text { Societal risk } \\
\text { [fatalities/yr] }\end{array}$ & 0.28 & 0.24 \\
\hline $\begin{array}{c}\text { Economic risk } \\
{[\mathrm{M} \text { EUR/yr] }}\end{array}$ & 2.10 & 1.89 \\
\hline
\end{tabular}

Table 6. Impact of PAMRI implementation on societal and economic risk.

Risk outcomes show a societal risk level up to 0.28 fatalities per year, with 1,168 annual expected affected population.

Societal risk after implementation of the Local Action Plan might change from 0.28 to 0.24 fatalities per year (i.e. a reduction about $14 \%$ ).

Economic risk in terms of annual expected damages would vary from 2.10 to 1.89 M EUR per year (i.e. a reduction about $10 \%$ ). Only direct benefits (such as the reduction in flood damage to buildings and assets) are included in the analysis of the impact of implementing the plan. Other benefits could be considered in future upgrades.

Figures 5 and 6 show F-D and F-N curves for both scenarios (Base Case, solid line, and Base Case including PAMRI implementation, dashed line). The vertical axis represents the annual exceedance probability $(\mathrm{F})$ of each level of potential consequences.

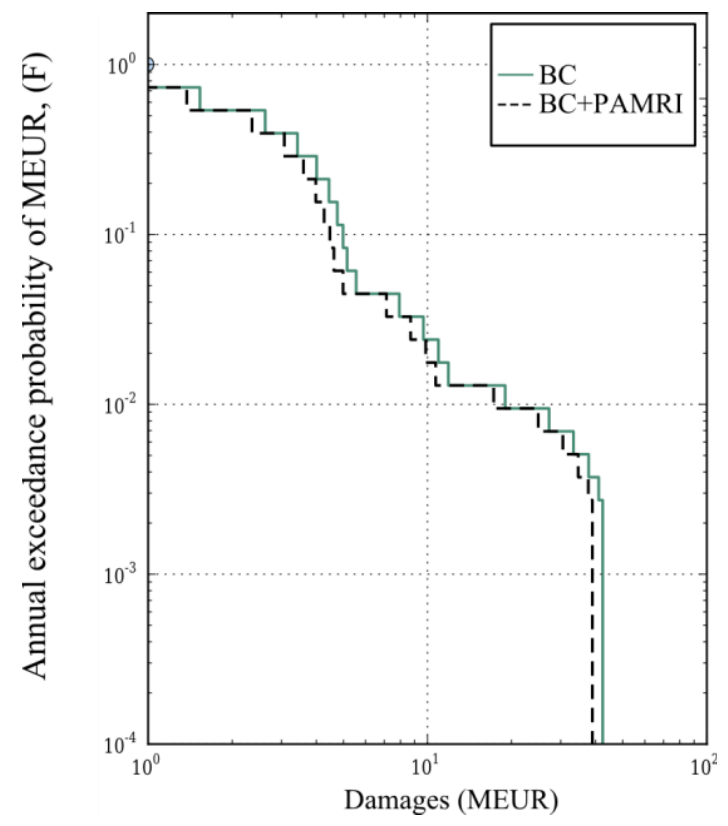

Figure 5. F-D graph. Source: (Castillo-Rodríguez et al., 2016)

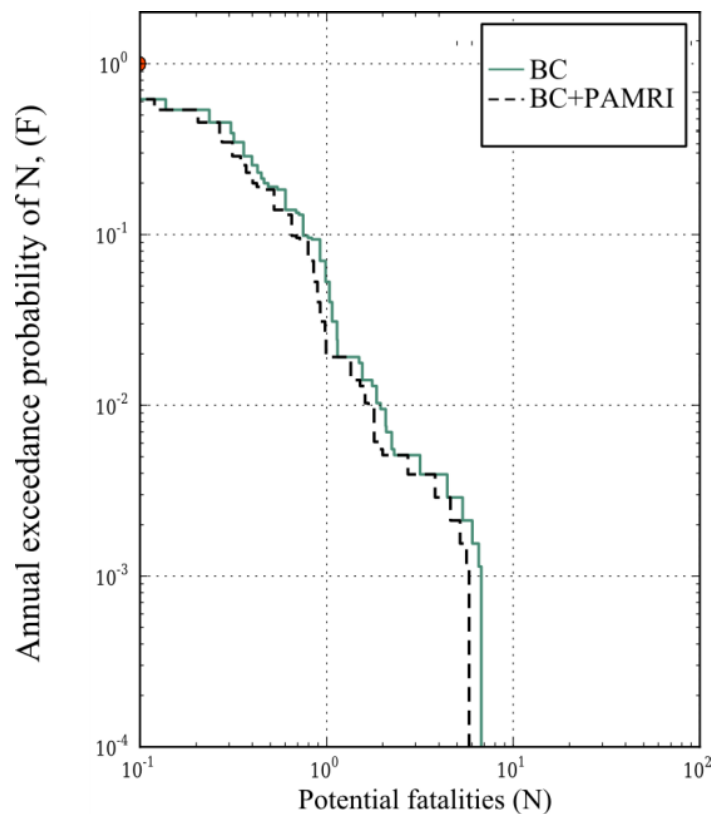

Figure 6. F-N graph. Source: (Castillo-Rodríguez et al., 2016)

\subsection{Implications for flood risk action planning}

The application of quantitative flood risk analysis for local flood risk planning for Oliva represents a novel analysis at regional and national scale.

Based on results from this analysis, the following recommendations were made to local authorities for defining strategies for local action planning, derived from 
outcomes of conducted flood risk analysis (CastilloRodríguez et al., 2016):

- Upgrading hydraulic modeling to a broad set of flood events for hazard mapping, and analyzing not only river flooding but also pluvial or coastal flooding.

- Improved data gathering on population characteristics and distribution at local scale.

- Definition of specific public education campaigns for resident and seasonal population, with emphasis in high vulnerable groups (e.g. the elderly, schools and campsites).

- Definition of a specific procedure to formally reporting flood events, damages and effect of communication and evacuation procedures for future updates of hazard and vulnerability analysis.

- Verification of established communication schemes between regional and local authorities, and with emergency and civil protection services to ensure effectiveness of non-structural measures for flood risk reduction.

- Potential locations for assembly points and helicopter landing sites have been set based on population clusters, hazard maps, and available evacuation routes. These sites should be verified and reviewed in future updates.

- Data gathering on additional urban characteristics (e.g. building typology, daily variability of population in industrial and commercial areas, etc.) is encouraged to upgrade risk analyses and provide improved outcomes for decision making.

- Future flood risk mitigation measures should be planned to reduce annual expected affected population. If societal risk tolerability criteria are not available or applicable, strategies might be defined in accordance with the ALARP principle (As Low As Reasonably Practicable), used in other safety applications (SPANCOLD, 2012).

These recommendations were established to support local action planning from a risk-informed vision.

\section{Content of the plan}

Following the structure established by regional policy, the plan is divided in 6 documents as follows:

-Doc. 1: Fundamentals

-Doc.2: Risk analysis

-Doc.3: Organization and structure

-Doc.4: Operation

-Doc.5: Implementation and maintenance

-Doc.6: Annexes

The last document includes 10 annexes with the following additional information:

-I: Approval

-II. Resources
-III. Directory

$\bullet$ IV. Maps

$\bullet V$. Monitoring

-VI. Implementation and maintenance

-VII. Advice to the public

-VIII. Dam emergency action plan

-IX. Data gathering

-X. Risk analysis: detailed description

The Plan includes the description of the urban area, results from conducted flood risk analyses and all required information, procedures and actions to be accomplished in case of emergency.

As an example, Fig.7 shows the communication scheme included in Doc. 3 in case of Meteorological Alert due to intense rainfall. The Plan describes communication schemes, tasks and actions to be undertaken (e.g. monitoring, advice to the public, etc.) for different emergency phases (Alert, Pre-emergency and Emergency).

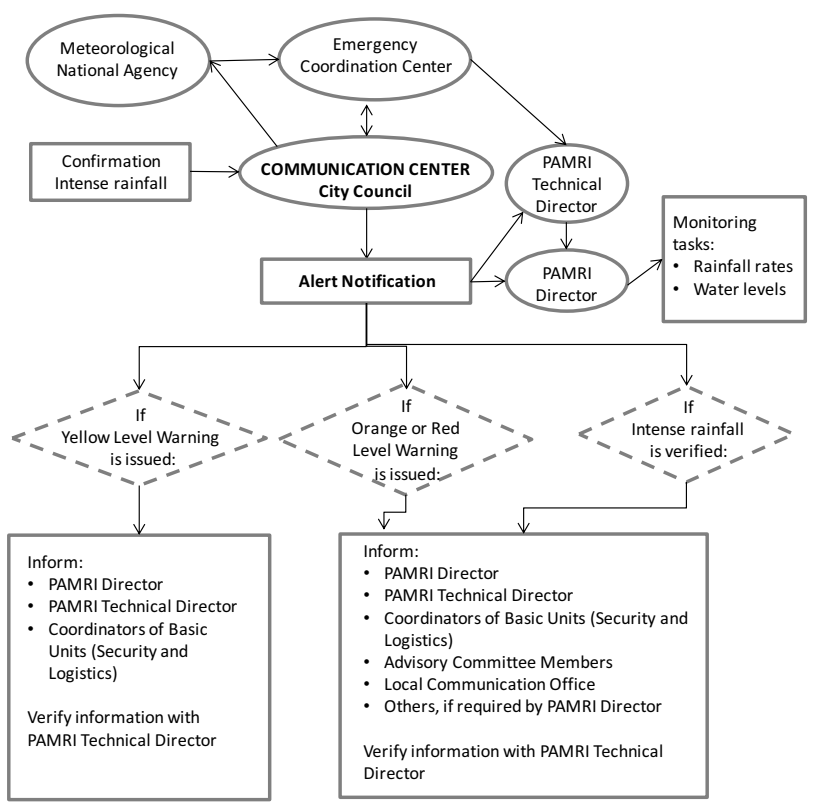

Figure 7. Example of communication scheme (Phase: Alert). Source: (Oliva City Council, 2015).

In Annex X, the detailed flood risk analysis summarized in this paper is described.

\section{Implementation of the plan}

The plan was approved by Oliva City Council in January 2016. After being validated by the Regional Government, the plan will be implemented within the next 9 months (as stated in Doc.6, Annex VI).

Implementation actions are established based on three main objectives:

-Verification and improvement (if required) of infrastructure, means and resources related to the Local Action Plan.

- Information and training for all actors involved in each stage of the Plan.

- Public education and information campaigns. 
Concerning the third implementation edge, public education and information campaigns will focus on increase risk awareness and to promote the local civil protection and flood risk management strategy. Specific characteristics of local population will be considered in the definition of information campaigns during the implementation phase, with focus on seasonal visitors and vulnerable areas (e.g. campsites). Therefore, information campaigns will preferably be conducted in May or June, at the starting period of the summer season, and late August (before the rainy season).

In addition, relevant information will be available permanently from the City Council website in different languages and submitted through the mobile application "Oliva report".

\section{Updating and upgrading the plan}

The Plan should be updated and upgraded, with the aim of accomplishing the following objectives:

- Keep the content up-to-date and perform periodic evaluations of local flood risk management actions derived from the Plan.

- Improve risk awareness at all levels, from decisionmakers to the public.

- Ensure that the public receives up-to-date and valuable information concerning how to act before, during and after an emergency.

It is established that updates of the Plan will be conducted yearly (and after any significant flood event) to consolidate data collection, reporting, and lessons learnt.

\section{Conclusions}

There are lots of challenges that local governments are facing: lack of resources, the need for engaging flood risk management actors and citizens; climate change impact; a changing socio-economic context; and, new technologies that change the way we communicate (in our daily life and during an emergency event).

Engaging citizens and local communities is crucial for improving risk communication and awareness, and consequently, for reducing risk. Working with citizens allows local governments to define flood risk strategies based on actual needs and population behaviour.

Information before, during and after a flood event should be submitted in the correct manner and through the appropriate communication method. In this sense, local action plans are essential for defining the correct actions to be undertaken.

The performed flood risk analysis has shown the impact of local action planning on societal and economic risk. Consequently, local action plans should include not only up-to-date and effective communication schemes but also adequate tasks concerning public education to reduce societal risk, especially in cities with high seasonal variation of population.

In the next years, ongoing urban transitions (e.g. from "grey" to "green" solutions for flood risk reduction) and ageing population will modify the current urban landscape. Hence, it is important to adapt flood risk management strategies to this changing urban environment. Updating and upgrading risk analyses and improving action plans will help local authorities to define actions in a more efficient and effective way.

The presented study is an example for other cities on how quantitative flood risk analyses may support local action planning. A more comprehensive risk analysis might be carried out to include other sources of flood hazards such as pluvial or coastal flooding. The combination of multiple flood hazards should be taken into account in future risk analyses.

\section{References}

References cited in this paper include:

Castillo-Rodríguez, J. T., Escuder-Bueno, I., AltarejosGarcía, L. and Serrano-Lombillo, A.: The value of integrating information from multiple hazards for flood risk analysis and management, Nat. Hazards Earth Syst. Sci., 14(2), 379-400, doi:10.5194/nhess-14-379-2014, 2014.

Castillo-Rodríguez, J. T., Escuder-Bueno, I., PeralesMomparler, S. and Porta-Sancho, J. R.: Enhancing local action planning through quantitative flood risk analysis: a case study in Spain, Nat. Hazards Earth Syst. Sci. Discuss., 1-36, doi:10.5194/nhess-2016-65, 2016.

DEFRA: FD2321/TR1 The Flood Risks to People Methodology, London. [online] Available from: www.defra.gov.uk/environ/fcd/research, 2006.

Escuder-Bueno, I., Castillo-Rodriguez, J. T., Zechner, S., Jöbstl, C., Perales-Momparler, S. and Petaccia, G.: A quantitative flood risk analysis methodology for urban areas with integration of social research data, Nat. Hazards Earth Syst. Sci., 12, 2843-2863, doi:10.5194/nhess-12-2843-2012, 2012.

Generalitat Valenciana: Plan de Acción Territorial sobre prevención del Riesgo de Inundación en la Comunitat Valenciana (PATRICOVA), Valencia., 2015.

iPresas Risk Analysis: iPresas Calc, [online] Available from: www.ipresas.com, 2014.

MAGRAMA: Propuesta de mínimos para la metodología de realización de los mapas de riesgo de inundación, Madrid., 2013.

Oliva City Council: Plan de Actuación Municipal ante el Riesgo de Inundaciones (PAMRI), Oliva (Spain)., 2015.

Penning-Rowsell, E., Floyd, P., Ramsbottom, D. and Surendran, S.: Estimating Injury and Loss of Life in Floods : A Deterministic Framework, Nat. Hazards, 36, 43-64, 2005.

SPANCOLD: TECHNICAL GUIDE ON RISK ANALYSIS APPLIED TO MANAGEMENT OF DAM SAFETY, edited by Spanish National Commitee on Large Dams, Spanish Professional Association of Civil 
Engineers, Madrid., 2012.

Ward, P. J., De Moel, H. and Aerts, J. C. J. H.: How are flood risk estimates affected by the choice of returnperiods?, Nat. Hazards Earth Syst. Sci., 11(12), 31813195, doi:10.5194/nhess-11-3181-2011, 2011. 